\title{
Analysis on Safety Control Technology of Construction Management
}

\author{
Chenghua Guo \\ Liaoning Jianzhu Vocational College, Liaoyang, Liaoning, 111000
}

\begin{abstract}
With Chinese accession to the WTO, China' s security legal system continues to improve, the traditional security management has been incompatible with the current level of development. Although our safety management level is improving, but the lack of safety management procedures and systematic, human factors still occupy an important position, prevention management is not a relatively clear basis. The same enterprise, in the same rules and regulations, in different projects because of the experience of safety management personnel and work experience, project management level is also very different. Experienced, long working hours of personnel management is relatively in place, relatively speaking, the lack of a certain practice in the field, relying solely on safety technology measures, and safety technology measures targeted and operability in the current state is not very In place, it is difficult to accurately determine the existence of risk sources in the operation, so that the sensitivity of the problem will be greatly reduced, prevention and management will be difficult to really be achieved. From the above analysis can be seen, the construction market economy is still quite a period of time in the future of Chinese national economy is an important part. In the process of building construction, construction site safety management is a very important issue. At present, the mode and method of safety management are generally lack of pertinence.
\end{abstract}

Keywords: Safety Control, Construction Management, Safety Technology 


\section{Introduction}

Safety management is an important part of enterprise management, the level of safety management, the relationship between the survival and development of enterprises, the relationship between the lives and well-being of workers, the relationship between the family's happiness. For a long time, safety management in the enterprise has also been a certain degree of development, enterprise safety management level continues to increase. China adhere to the "safety first, prevention first" safety policy, in the management process to continuously improve the safety laws and regulations, promulgated and implemented in 2003, "the People's Republic of China Production Safety Law" is the basic law of Chinese security management. As a high-risk industry, one of the construction industry, in order to regulate the safety management of construction enterprises, February 1, 2004 implementation of the "Construction Safety Production Regulations", shows that from the country to industry, enterprises, have put safety management is important Of the agenda. However, Chinese production safety situation is still very grim. Over the years, the number of major malignant accidents and occupational accidents frequently high, has been plaguing Chinese social stability and economic development. Since the reform and opening up, Chinese national economy has maintained rapid growth, but occupational safety is far behind the pace of economic construction. The legal system is not perfect, the information management system is imperfect; The safety basic research and the application technology are backward; The safety management system is not perfect; The security basic research and the application technology is backward; Many enterprises, especially small and medium-sized enterprises, have invested too little in security.

\section{Current Situation of Safety Management in Construction Enterprises}

Although the construction safety production in China has made certain achievements, the overall situation of safe production is relatively stable, but the total number of construction casualty accidents and the frequency of accidents did not decline significantly, the situation in some areas of serious production safety situation has not been fundamentally reversed. Mainly in: First, the number of construction accidents and the number of deaths is high. In 2000, there were 1013 cases, 1180 deaths, 923 cases occurred in 2001, 1097 deaths, 846 cases occurred in 2002, 987 deaths, 1004 cases occurred in 2003, 1045 deaths in 2004, 1208,1292 people died. In the first half of 2005, there were 519 construction accidents and 582 deaths in the country. Compared with the same period of the previous year, the number of accidents and the death toll increased by $24.5 \%$ and $20.7 \%$ respectively; the other was some major economic provinces (municipalities) The number of casualties increased with the scale of construction, such as Zhejiang Province, 2000 to 2002, respectively, the total construction 
output value of 138.376 billion yuan, 176.845 billion yuan and 208.952 billion yuan, while the construction of the death toll was 53, 79 and 86 persons. Guangdong, Shanghai, Jiangsu and other provinces and municipalities also have similar situations. Third, construction accidents or concentrated in the special treatment of the project. Using the current construction safety inspection standard (JGJ59-99) in China, the causes of 810 fatal accidents in the five years from 1996 to 2000 are analyzed. It can be seen that the factors such as height falling, electric shock, object attack, mechanical injury, Construction collapse is still the main type of accident.

\section{Analysis of the Causes of Current Building Safety Accidents in China}

The change of the construction investment system in our country makes the original construction production safety management no longer adapt to the present construction production mode. Therefore, there have been many management loopholes in the government-led safety management, and the laws and regulations concerning the construction safety are not perfect, The efficiency of government supervision is low, the social supervision system is imperfect, and the safety management is not in place. The construction safety management system which is suitable for market economy and legal and economic means has not been formed yet. Generally speaking, the system of safety production management in foreign advanced industrial countries is composed of four parts: "national supervision, corporate responsibility, insurance control and industry consultation". In fact, a good system and restraint mechanism is more important than regulation. With the regulatory approach, every day to check, you check to him if you eat dinner, accommodating relationship, but not easy to handle. So we must rely on institutional constraints, rather than by investing a lot of manpower and resources to engage in various forms of inspection.

Chinese law is too weak in its environment and health. There are some relevant provisions in the current "Building Law" in the "Chapter V Construction Safety Management". However, the emphasis on "environment and health" in construction activities has become an international topic of common concern. The target system of engineering construction has shifted from the traditional system of "cost-price to quality-time limit" to "cost-price-quality-time limit-environment and health". International Organization for Standardization has also developed a 1S014000 environmental management system. In addition, the OHSAS18000, an occupational health and safety assessment system developed by 13 organizations, including the National Institute of Standards and the National Institute of Standards and Standards, is also influential. Chinese accession to WTO has been equated with the $1 \mathrm{~S} 014000$, and promulgated GB-T28000 occupational health and safety management system. However, the Building Code has not yet reflected this trend. There is a phenomenon of subcontracting and anchoring too much, by calling and subcontracting a lot of qualified units and individuals can not enter 
the construction market, seriously disrupting the order of the market. The "Building Law" in Article 26 of the provisions of the clear can not be subcontracted and anchored.

As Chinese implementation of the "national monitoring, industry management" of the construction safety management system, therefore, the State Administration of Work Safety and local production safety supervision and administration of the implementation of the national supervision function, the Ministry of Construction and local construction administrative departments The implementation of industry management functions. However, with the deepening of the reform of our political system, the reform of state institutions, enterprise restructuring, enterprises gradually divorced from the shackles of industry administration, as the market independent of the main actors. In line with this, the Ministry of Construction and local construction administrative departments should also be the original industry administration to the national macro-control and market supervision of the functions of the national construction safety special supervisory functions of the performers, the State Administration of Production Safety Supervision and Administration and Local production safety supervision and management institutions at all levels have become the national safety of the overall performance of the supervisory functions. However, in the process, due to the development of Chinese security intermediaries and industry organizations lagging behind, the Ministry of Construction and the local construction administrative departments and other government agencies can not change the functions in one step, in fact, or perform part of the industry management functions. Resulting in lack of energy, management is not in place, can not keep up with the economic situation, the inevitable emergence of safety management vacuum.

\section{Countermeasures for Safety Management of Construction Site}

Accident control refers to the comprehensive elimination of the accident before the accident causes, and to reduce the probability of causing the accident, after the accident to reduce the seriousness of personnel and economic losses. The basic content of accident control includes two aspects: First, before the accident, the complete elimination of the root causes of accidents to minimize the probability of accidents; Second, efforts to reduce the loss after the accident. Accident prevention and accident suppression are the basic techniques of accident control, the former is the control measures before the accident, the latter focuses on the accident and after the accident control measures.

Accident prevention is to take various preventive measures to maximize the elimination or reduction may cause accidents of various potential factors. There are two ways of accident prevention. One approach is engineering physics, which is based on the energy release theory of Hatton. It mainly focuses on the prevention of the material factors of the accident. The measures include 
preventing the risk factors, reducing the existing risk factors, Risk factors in time and space; with obstacles to isolate risk factors; to improve the basic nature of risk factors; to strengthen the ability of risk units, such as protection; another human behavior law, the theory is based on Heinrich's accident causal chain theory, The main focus on standardizing the behavior of the person causing the accident; the measures taken include: ideological education, technical training to strengthen, not in the vicinity of risk factors for no reason to stay.

Accident suppression refers to the means to reduce the extent of the loss and take the rescue measures after the accident when the accident is happening or has ended. The loss of control can be taken after the loss of control measures are: to prevent the emergence of new sources of danger; to reduce the factors that constitute the source of danger; to prevent the proliferation of existing hazards; reduce the rate of dangerous proliferation, limiting dangerous space; in time and space Isolate the object of danger and protection; isolate the danger from the object to be protected by means of material barrier.

\section{Conclusion}

Safe production is the basic condition for protecting the workers' safety and health and ensuring the sustainable development of the national economy. Construction site is full of a lot of security risks, all kinds of unstable factors at any time may lead to accidents, a serious threat to the lives of construction workers. At present, China has promulgated a series of laws and regulations on construction safety production and management, and actively promotes the occupational health and safety management system. However, due to many practical problems, the situation of production safety is still very serious. In order to help enterprises to understand the level of safety management at the construction site, a clear direction for future improvements, while its level of safety management to provide scientific methods and means.

\section{References}

[1] Wang Wenzheng, Wang Yang. Construction project safety law enforcement supervision and six safety management system discussion $[\mathrm{J}]$. Construction Safety, 2005 (08)

[2] Li Shirong, Zhu Huiying. Building safety management in the UK [J]. Architecture, 2005 (04)

[3] Zhao Aiguo. Foreign industry safety development process of development [J]. Modern Occupational Safety, 2004 (08)

[4] Fan Xinhe. Analysis of the current safety problems in construction and countermeasures [J]. Huaibei Vocational and Technical College, 2004 (02)

[5] Tian Yuanfu, Li Huimin. Chinese construction safety management status and thinking [J]. Chinese Journal of Safety Science, 2003 (12) 